\title{
What is the prognosis of women with polycystic ovarian syndrome compared to other women of similar age in fertility units?
}

De la Fuente Bitaine Laura ${ }^{1}$; Villalain Gonzalez Cecilia ${ }^{1}$;Álvaro Valiente Laura ${ }^{1}$; Abad Gran Magdalena'; Ruiz Azqueta Nerea $^{2}$; Escalante Bermúdez Elisa ${ }^{2}$; Moreno Fernandez Pilar ${ }^{2}$ : Palomo Balda Maria Luisa ${ }^{1}$; Carrera Roig Maria ${ }^{1}$

1Obstetrics and Gynecology, Hospital Universitario 12 de Octubre, Madrid, Madrid, Spain ${ }^{2}$ Biology Department. Fertility and Sterility Unit, Hospital Universitario 12 de Octubre, Madrid, Madrid, Spain

\section{Problem statement}

Polycystic ovarian syndrome (PCOS) is one of the main causes of sterility in women, because of its physiopathology associating ovarian dysfunction with oligo-ovulatory and anovulatory cycles. Ovarian steroidogenesis dysfunction often requires assisted reproductive techniques (ART) leading to characteristic ovarian response. Our study intends to analyze PCOS patients characteristics and outcomes when atteding a fertility unit (FU)

\section{Methods}

We present a retrospective cross-sectional study set in the FU in Hospital 12 de Octubre, Madrid. We recruited 204 women between January 2015 and June 2016. 102 as they were diagnosed of PCOS according to Rotterdam criteria and constituted group 1. Group 2 was integrated by 102 control patients matched by age and enrolment on FU. Techniques performed were either intra-uterine insemination (IUI) or in vitro fertilization (IVF) depending on the patient's characteristics.

Requirement to start an ART in our unit is to have an adequate metabolic status: body mass index $(\mathrm{BMI})<30 \mathrm{~kg} / \mathrm{m}^{2}$ and glycemic/insuline levels and blood pressure within normal values. If those criteria are not met, dietary and exercise recommendations are given, and medical treatment started if necessary (antihypertensive or metformin). As a public hospital, ART are reimbursed, with limited indication criteria and 4month delay to start IVF cycle and none for IUI.

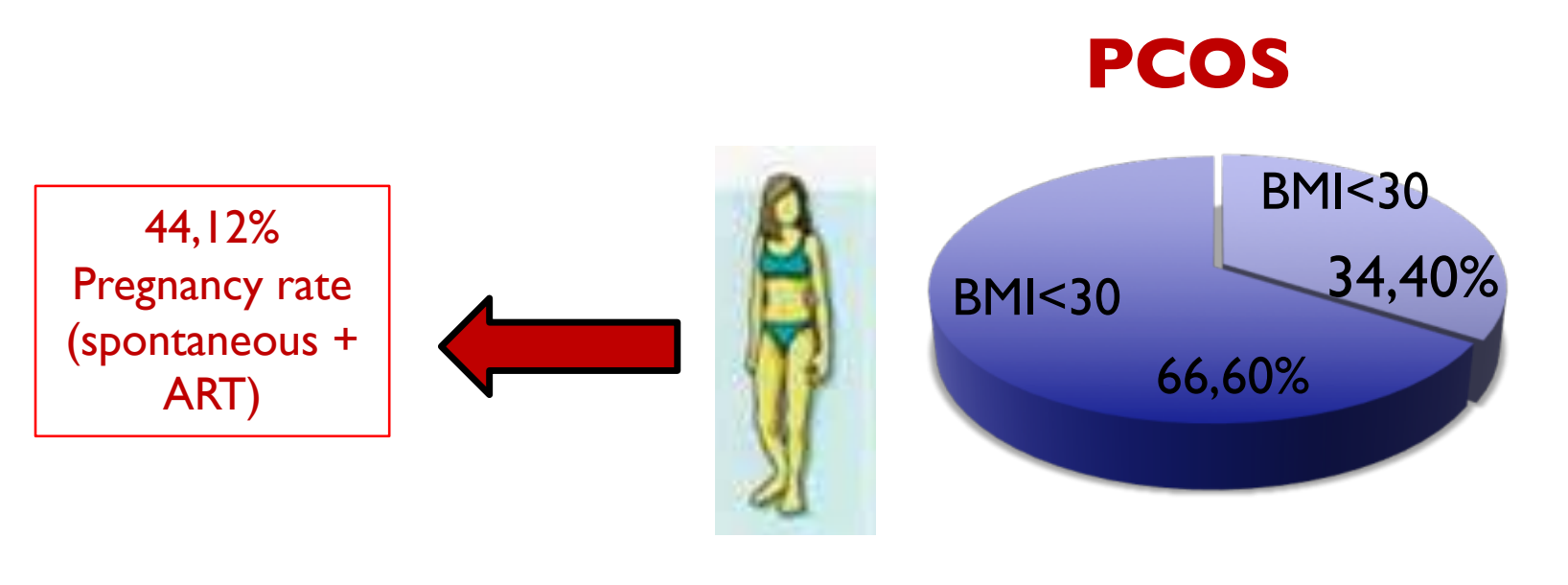

\section{Results}

\begin{tabular}{|l|c|c|}
\hline $\begin{array}{l}\text { Patients basal } \\
\text { characteristics }\end{array}$ & PCOS $(\mathrm{n}=102)$ & Control $(\mathrm{n}=102)$ \\
\hline Previous abortion \% & 14.99 & 23.99 \\
\hline $\mathrm{BMl}$ in $\mathrm{kg} / \mathrm{m}^{2}$ (mean, SD) & $29.03(6.42)$ & $23.58(4.12)$ \\
\hline $\begin{array}{l}\mathrm{FSH} \text { in } \mathrm{mlU} / \mathrm{mL} \text { (mean, } \\
\mathrm{SD})\end{array}$ & $6.24(5.3)$ & $6.24(5.3)$ \\
\hline $\begin{array}{l}\text { Antral follicle count } \\
\text { (mean, SD) }\end{array}$ & $22.89(5.67)$ & $12.60(5.94)$ \\
\hline
\end{tabular}

BMI, body mass index; PCOS, polycystic ovarian syndrome; SD, standard deviation

\begin{tabular}{|l|c|c|}
\hline & PCOS $(\mathrm{n}=102)$ & Control $(\mathrm{n}=102)$ \\
\hline $\begin{array}{l}\text { Delay to ART in days } \\
(\text { mean, SD) }\end{array}$ & $160.77(95 . \mathrm{II})$ & $190.76(\mathrm{I} 47.6)$ \\
\hline Start at IUI \% & 50.88 & 21.56 \\
\hline Requirement of IVF (\%) & 59.3 & 89.2 \\
\hline $\begin{array}{l}\text { Hyperstimulation (freeze } \\
\text { all) in \% }\end{array}$ & 4 & 1 \\
\hline $\begin{array}{l}\text { Global pregnancy rate } \\
\text { (spontaneous + IUI+ IVF)\% }\end{array}$ & 23.63 & 27 \\
\hline
\end{tabular}

ART, assisted reproductive techniques; IUI, intra-uterine insemination; IVF, in vitro fertilization

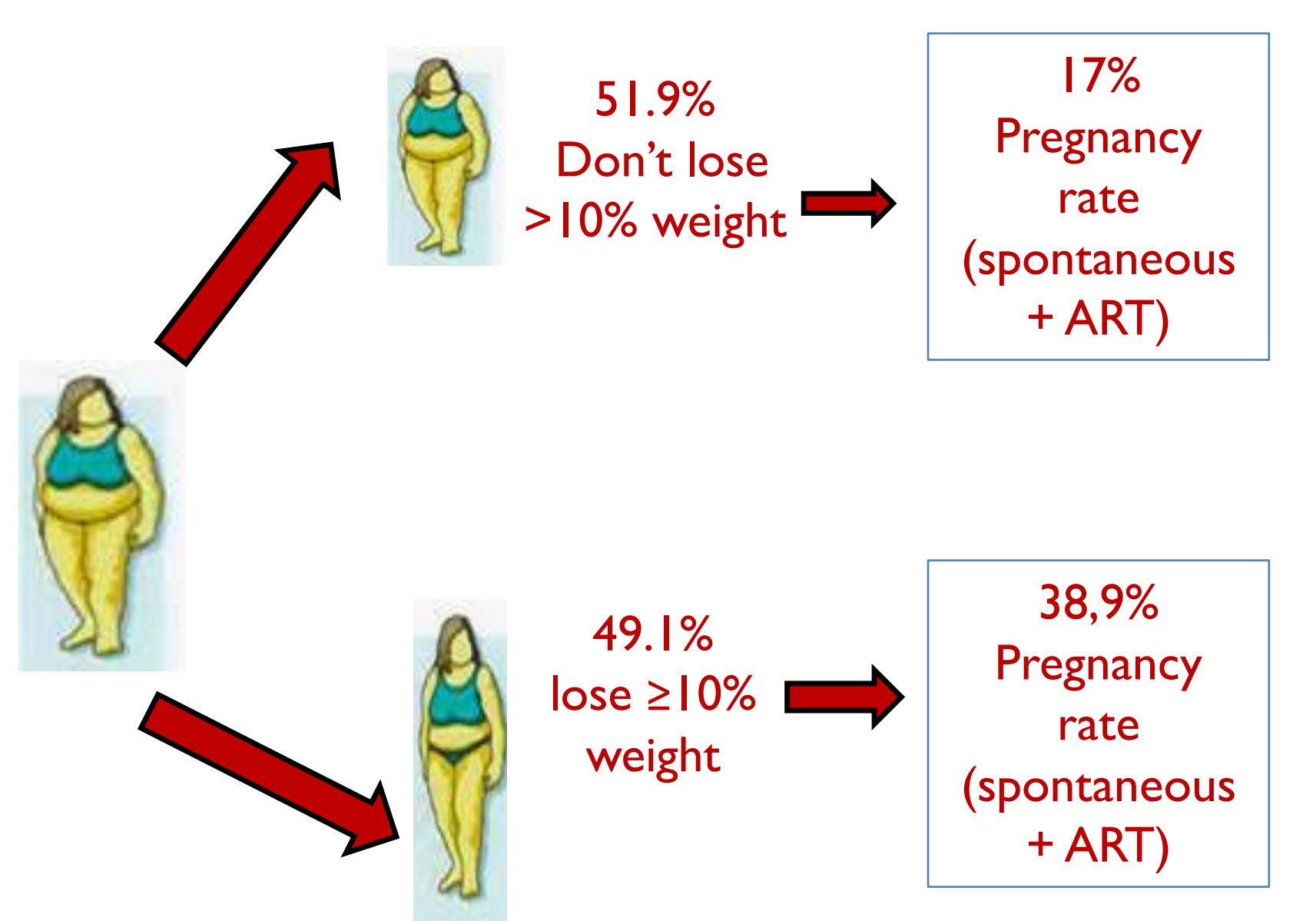

\section{Conclusion}

Results on PCOS patients did not exceed those of the rest having longer waiting lists as most of them needed to reach an adequate basal metabolic status. Given that the metabolic basal status of patients with PCOS is key on the reproductive future of the woman as well as on the outcome of reproductive assisted techniques it is essential to educate younger patients to follow a healthy diet and exercise to meet the best basal status possible. 